\title{
Bioavailability and the Bioequivalence of Conjugated Fatty
}

\section{Acids}

\author{
Mancini Filho J*, Melo ILP, Sattler JAG and Yoshime LT \\ Department of Food Science and Nutrition, Faculty of Pharmaceutical Sciences, \\ University of São Paulo, São Paulo, Brazil
}

Mini Review

Volume 1 Issue 1

Received Date: May 26, 2017

Published Date: June 12, 2017

*Corresponding author: Mancini Filho J, Department of Food Science and

Nutrition, Faculty of Pharmaceutical Sciences, University of São Paulo, São Paulo, Brazil, Email: jmancini@usp.br

\section{Mini Review}

Several studies with conjugated fatty acids have been carried out by our group. They have been proposed by the authors of this Mini Review for more than 30 years. This particular research with conjugated fatty acids was started and developed more than six years ago. The study's aim has been to clarify their aspects of safety, bioavailability, and functionality.

Conjugated fatty acids mainly originate from the linoleic (CLA) and the linolenic (CLNA) fatty acids, through chemical, enzymatic and metabolic processes. As for their structural forms, they can be characterized when they are compared to the fatty acids that gave rise to them, where the change from unconjugated double bonds to conjugation occurs. That is, where methylene carbon ceases to exist between them. A further important aspect is the spatial alteration of the hydrogens that are bound in the double bonds, which in the cis form change into trans [1].

The fatty acids that are present in vegetables, animal oils, and fats, become bioavailable to humans, as well as any other fatty acids that are present in the triglycerides. This activity occurs through the action of the lipases that hydrolyze and release them, establishing the conditions for the organisms to transport them to the circulatory current in levels of $90 \%-95 \%$.

Due to the peculiar characteristics of the conjugated fatty acids, several studies have been carried out. Various changes in the organisms that consume them and the search for their equivalence when in comparison to other bioactive compounds have been highlighted. This has been through the studies that have aimed at the alterations of body composition [2]. For instance, this would include the LDL / HDL lipoprotein ratios and their anti-inflammatory actions among others [3-7].

Our initial work was aimed at the incorporation of these conjugated fatty acids into bovine tissues, since they may be present as a function of the enzymes of ruminant animals, causing them to be bioavailable fatty acids. The previous results have shown high concentrations of these conjugated fatty acids in the fats that cover the muscle, reaching almost $3 \%$, as well as in the muscle itself and in the internal fat, reaching approximately $1 \%[8]$.

Therefore, this was indicative that conjugated fatty acids from animal foods (i.e., ruminants), which are present in CLA, resemble the mechanisms and the benefits of CLNAs, especially: the induction of lipolysis by catecholamines; providing the selective reduction of visceral fat; and indirectly, abdominal fat. This is together with increases in the activities of the hormonesensitive lipase enzymes, and consequently, the lipolysis in adipocytes, accompanied by a greater oxidation of the fatty acids in both the skeletal muscles and the adipose tissues. In addition, there are increases to be found in the activities of Carnitine Palmitoyltransferase, with its thermogenical effects related to an induction in the gene expressions of Uncoupling Proteins (UCPs).

Aspects focused on plant food have also been the targets of our research. Studies on the oils from the seeds of Bitter Melon (Momordica charantia L.) and Pomegranate (Punica granatum L.), which have $\alpha$ Eleostearic conjugated fatty acids $(18: 3,9 c 11 t 13 t)$ and 
Punicic acid (18: 3, 9c11t13c), respectively, are examples of our work.

It was observed that conjugated fatty acids (CLNAs) increased the activities of Superoxide Dismutase (SOD) in the livers of those animals that consumed $2 \%$ to $4 \%$ of pomegranate seed oil. The study has also observed the bioconversion of CLNAs to CLAs, which may be the inducers of SOD activities [9].

Currently, when using CACO-2, HepG2, 3T3-L1, and RAW 264.7 cell cultures, we are seeking information on the bioequivalence of conjugated fatty acids, in the processes of inhibitions of Cyclooxygenase 2, as well as in the actions that lead to the formation of eicosanoids, resulting from the oxidation of arachidonic acid, which is a pro-inflammatory compound. These cell cultures also inhibit lip polysaccharides (LPS), which are responsible for the enlargement of the inflammatory processes. This is while at the same time, they participate in an inhibition of nuclear factor kappa $B$ $(\mathrm{NF}-\kappa \mathrm{B})$, both in the cytoplasm and in the cell nuclei, being part of the degenerative processes. These compounds are also related to the cytokines that participate in inflammation, together with its inhibition.

From the observations presented here, it can be inferred that conjugated fatty acids present expressive bioavailability, with their bioequivalence highlighted in several metabolic processes. Studies should be expanded on the participation of these fatty acids, confirming or evaluating their metabolic processes, as well as for the identification of new functionalities of the same.

\section{References}

1. Melo ILP, Carvalho EBT, Mancini Filho J (2014) Pomegranate seed oil (Punica granatum L): a source of Punicic acid (conjugated alpha-linolenic acid). J Hum Nutr Food Sci 2(1): 1024-1034.

2. Park Y, Pariza MW (2007) Mechanisms of body fat modulation by conjugated linoleic acid (CLA). Food Res. Int 40: 311-323.
3. Wanders AJ, Brouwer IA, Siebelink E, Katan MB (2010) Effect of a high intake of conjugated linoleic acid on lipoprotein levels in healthy human subjects. PLoS ONE 5(2): e9000.

4. Ebrahimi-Mameghani M, Jamali H, Mahdavi $\mathrm{R}$, Kakaei F, Abedi R, et al. (2016) Conjugated linoleic acid improves glycemic response, lipid profile, and oxidative stress in obese patients with nonalcoholic fatty liver disease: a randomized controlled clinical trial. Croat Med J 57(4): 331341.

5. Mitchell PL, McLeod RS (2008) Conjugated linoleic acid and atherosclerosis: studies in animal models. Biochem Cell Biol 86(4): 293-301.

6. Viladomiu M, Hontecillas R, Bassaganya-Rieva J (2016) Modulation of inflammation and immunity by dietary conjugated linoleic acid. Eur J Pharmacol 785: 87-95.

7. Reynolds CM, Roche HM (2010) Conjugated linoleic acid and inflammatory cell signaling. Prostaglandins Leukot rienes and Essential Fatty Acids 82(4-6): 199-204.

8. Pinheiro FG (2010) Ácido linoleico conjugado em cortes bovinos e laticínios: avaliação de metodologias analíticas para a quantificação dos isômeros conjugados major itários. Dissertation 52p.Faculty of Pharmaceutical Science University of São Paulo.

9. Melo ILP, Silva AMO, Carvalho EBT, Yoshime LT, Mancini-Filho J, et al. (2016) Incorporation and effects of Punicic acid on muscle and adipose tissues of rats. Lipids Health Dis 15: 40-46.

10. Melo ILP, Carvalho EBT, Silva AMO, Yoshime LT, Mancini-Filho J, et al. (2016) Characterization of constituents, quality and stability of pomegranate seed oil (Punicagranatum L). Ciencia e Tecnologia de Alimentos 36(1): 58-65. 